\title{
Preservar a memória do mestre Schenberg
}

José Luiz Goldfartb

M

ARIO Schenberg partiu numa tarde de sábado, 10 de agosto de 1990. Vinte anos nos separam desse entardecer tão especial, e vem aquela sensação estranha: "parece que foi ontem". De fato, desde a notícia de sua passagem ao entardecer, até o sepultamento no domingo seguinte no final da manhã, permaneci acordado acompanhando primeiramente as providências necessárias, e, a partir da noite, velando o grande cidadão paulistano no prédio aberto da Câmara dos Deputados no Ibirapuera. Noite longa e absolutamente inesquecível... Por ali passaram cientistas, políticos, militantes de muitos partidos, escritores, pintores, escultores, cantores, compositores, atores, religiosos, jornalistas, e também, muitos, muitos mesmo, cidadãos comuns. Homenagem, carinho, reverência, susto, tristeza, vazio, abismo... Rodas se formaram até de madrugada comentando a multifacetada trajetória do grande mestre. Consigo reviver a chegada de Haroldo e Augusto de Campos, Jacó e Guita Ginsburg, Amélia e Ernest Hamburger, Mário Gruber, Décio Pignatari, Fernando Henrique Cardoso, Alberto da Rocha e Silva, Simão Mathias, José Goldenberg, Jorge Mautner, e tantos outros grandes nomes das artes, ciência, política brasileiras. Recordo suas palavras sobre Schenberg, suas expressões diante do caixão; todos relataram histórias de vida que povoaram toda uma noite agradável de agosto, nem fria, nem quente... Uma ideia-sensação era pano de fundo ao que ocorria: preservar a memória de tudo o que foi e representou Mario Schenberg seria, a partir de então, missão de todos que ali se reuniam quase que numa verdadeira manifestação pública, verdadeiro happening, ao bom estilo do mestre, desafiador, ainda mais presente na despedida. Mas, claro, tarefa sabidamente quase impossível num país de tão pouca memória, especialmente de sua ciência e seus cientistas (como dói mencionar o nome Schenberg entre novas gerações e receber o silêncio).

E assim, desde 1990 eventos, publicações, palestras, conferências, simpósios, aulas inaugurais, vídeos, documentários, programas de rádio e TV, e-mails, sites, blogs, tweets, livros, artigos, nomeação de bibliotecas, laboratórios, escolas... Muita coisa é feita para mantermos viva a memória desse grande intelectual brasileiro que atuou com intensidade em tantas áreas ao longo de quase todo o século XX. É nesse contexto que recebemos em 2009 primorosa edição da Edusp da Obra cientifica de Mario Schönberg - volume 1 - de 1936 a 1948. Produção editorial impecável, capa dura com expressiva foto do mestre, papel de miolo, finíssimo "Chamois Fine Dunas", oferecendo agradável fundo amarelado às equações matemáticas e esquemas originalmente rascunhados por Schenberg e publicados em dezenas de importantes revistas científicas brasileiras e de todo o mundo. As coordenação, anotação, documentação e o magnífico prefácio introdutório não poderiam ser de outra senão Amélia Império Hamburger, discípula do mestre e dedicada permanentemente à preservação do homem e sua obra. Já em 1983 vim a trabalhar com Amélia Hamburger na edição do livro Pensando a física, transcrição revisada de palestras oferecidas por Mario 
Schenberg no Instituto de Física da USP no mesmo ano. Quase dois semestres de árduo trabalho semanal (reuniões em sua casa aos sábados pela manhã), quando pude comprovar a dedicação de Amélia Hamburger à preservação da palavra e pensamento de Schenberg; não apenas o apreço ao mestre, mas um carinho e paixão sem limites à pessoa Mario Schenberg; desde então pude também colaborar com muitas outras ações encetadas pela professora visando à divulgação da obra e da pessoa de Mario Schenberg. Agora, Amélia Hamburger supera-se e nos presenteia essa maravilhosa coletânea da obra científica de Schenberg. Esse livro apresenta uma reunião de trabalhos científicos do autor publicados entre 1936 e 1948. Os trabalhos referem-se ao período em que trabalhou no Brasil e fez estágios na Itália e nos Estados Unidos; o volume seguinte - que desde já aguardamos com muita ansiedade - cobrirá os anos de 1949 a 1977. A publicação dos escritos científicos de Schenberg em livro visa tornar mais conhecida e de fácil acesso uma produção de projeção internacional, em boa parte realizada no Brasil. A publicação dos textos é fiel aos textos originais em português, inglês, francês, italiano e espanhol.

Alguns aspectos da relevância internacional de Mario Schenberg saltam aos olhos ao percorrermos a coletânea: Schenberg trabalhou e publicou com grandes nomes da física do século XX; esteve envolvido em pesquisas nos principais temas da ciência que moldaram nossa visão de mundo na atualidade, sempre viajando pelos quatro cantos do planeta, visitando os principais centros de investigação. Citemos alguns nomes que se destacam nos artigos reunidos nesse volume 1 , e que evidenciam com quem o brasi- leiro Schenberg estava "antenado": G. P. S. Occhialini, Abrahão de Moraes, G. Gamow, S. Chandrasekhar, C. M. Lattes, Walter Schützer; são nomes fundamentais para conhecermos tanto a história da física no Brasil como no cenário internacional (alguns laureados com o Prêmio Nobel) no século XX. Mas não apenas esteve Schenberg ao lado de outros importantes cientistas ao elaborar suas reflexões e trabalhos, espalhados literalmente em países dos quatro continentes - o que evidencia que, muito antes da internet, a ciência já era uma prática absolutamente globalizada -, mas também ficamos surpresos com a variedade de temas abordados com competência, ousadia e ineditismo pelo grande mestre da física teórica brasileira. Novamente vamos percorrer os artigos reunidos por Amélia Hamburger, agora atentando a alguns títulos para perceber a enorme vastidão de temas estudados por Schenberg: "Sull'interazione degli elettroni", "Um novo tipo de integrais generalizadas de Fourier", Relativistic commutation rules in the quantum theory of fields", "Sobre uma componente ultramole da radiação mole", "Processi Moltiplicativi della radiozione cósmica nell'alta atmosfera", "Sobre as equações inomogêneas de movimento na mecânica quântica”, "Equações relativísticas de movimento de $1^{\text {a }}$ ordem na mecânica quântica", "Ordem da componente dura da radiação cósmica", "Sobre a equação dos dielétricos reais", "The possible role of neutrinos in stellar evolution”, "Angular Momenta of Gravitational fields", "Neutrino Theory of stellar collapse", "On the theory of integer spin mesons", "The hamiltonian formalism of relativistic dynamics Teoria do Elétron Puntiforme", "Classical Theory of the Electron", "Estados da energia negativa do elétron”, "Quantum Theory 


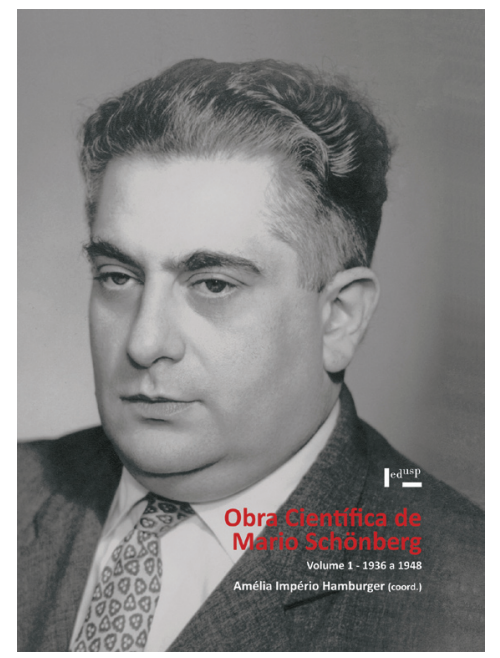

SCHÖNBERG, M. Obra científica de Mario Schönberg. Coord. Amélia Império Hamburger. São Paulo: Edusp, 2009. v.1: De 1936 a 1948.

of the Electron". Cada artigo, cada contribuição, exige muitas horas, dias, meses e até anos de estudo para compreender as reflexões físico-matemáticas de Schenberg; mas apenas observando os títulos compreendemos a amplitude: astrofísica (desvendando os processos envolvidos na evolução das estrelas - daí o famoso processo Urca, muito bem ilustrado na Obra cientifica de Mario Schönberg nas publicações com G. Gamow), teorias clássica, relativística, quântica do elétron, radiações cósmicas... Schenberg penetrou mistérios da matéria no micro e no macrocosmos.

Graças, porém, ao criativo "Prefácio introdutório - Anotações e documentos", de Amélia Império Hamburger, o livro não se restringe apenas ao "iniciado" na linguagem matemática dos artigos agrupados; cartas de e para Mario Schenberg e outros fragmentos de publicações variadas aparecem pela primeira vez em livro, comentados pela autora, inaugurando mais uma porta; um punha- do de documentos originais e que agora são publicados serão material de pesquisa e reflexão para novos estudos, trazendo nova luz à nossa compreensão da obra $\mathrm{e}$ pensamento de Mario Schenberg. Aqui comparecem correspondências trocadas e menções em outros textos de Clarice Lispector, Lygia Clark, Mario Gruber, Francisco Rebolo Gonsales, S. Chandrasekhar, David Bohm, Abrahão de Moraes, Gleb Wataghin, G. Occhialini, Guido Beck, Marcelo Damy, Leite Lopes, Luiz Freire, entre outros, e especialmente fragmentos de textos do próprio Mario Schenberg.

Com a riqueza dos documentos revelados e alinhavados, com maestria, por Amélia Império Hamburger, a Edusp coloca pérolas ao alcance de todos; que leituras atentas tragam novos olhares sobre a face multifacetada do brasileiro tão especial, para quem Haroldo de Campos dedicou as palavras, na contra capa do livro Diálogos com Mario Schenberg:

PARAFÍSICA

NO ESPAÇOCURVO

NASCE UM CRISANTEMPO

(PARA MARIO SCHENBERG)

"Um ser transeunte" (Gilberto Gil - vídeo Schenberguianas). E que Jorge Amado tão bem "fotografou":

Na universidade, na mostra de pintura, no comício, no meio da rua da multidão, na cadeia, no livro e no jornal, onde quer que se proteste contra a opressão, onde quer que se lute pela paz e pelo amor, ei-lo presente e militante. Não desanimou nem vacilou, assumiu o seu posto e continua. Um homem singular, um cidadão ilustre, um humanista que nos orgulha e honra. Um brasileiro chamado Mario Schenberg.

Essa publicação é mais uma ótima oportunidade para aproximarmo-nos 
desse homem múltiplo de Artes e Ciências que não conheceu as demarcações do especialista. Assim, um homem de nosso tempo:

[...] quem passa por ele na rua não desconfia disso. Mas quem convive um pouco com ele, percebe que não está tratando com um ser meramente terrestre. Há em seu rosto, em seu jeito de falar e de sorrir, sinais de quem já fez vertiginosas viagens ao avesso da matéria, de quem conhece as muitas velocidades em que ela se movimenta, se inventa e se dissipa. Mesmo assim, ele não se perde das pessoas. $\mathrm{O}$ estampido do cosmo não o ensurdeceu para a débil voz humana. (Ferreira Gullar - últimas duas citações do livro Mario Schenberg Entre-Vistas)

Sempre recomendada a preservação da memória de Mario Schenberg, e, portanto, mais que bem-vinda a nova edição da Edusp, obra premiada à altura do personagem em foco.

José Luiz Goldfarb é professor de pós-graduação em História da Ciência na Pontifícia Universidade Católica (PUC) de São Paulo. @ - jlgoldfarb@dialdata.com.br 